\title{
Ongoing Engagement in Organized Activities May Buffer Disadvantaged Youth Against Increasing Externalizing Behaviors
}

\author{
Alexander W. O’Donnell ${ }^{1}$ \& Bonnie L. Barber ${ }^{1}$ \\ ${ }^{1}$ School of Applied Psychology, Griffith University, Gold Coast, Australia
}

\section{Correspondence}

Please correspond with the lead author, Alexander W. O’Donnell, via email (alex.odonnell@griffith.edu.au).

\section{Acknowledgements}

The Youth Activity Participation Study of Western Australia (YAPS-WA) was supported through three Grants under the Australian Research Council's Discovery Projects funding scheme awarded to Bonnie Baber and Jacquelynne Eccles (DP0774125 and DP1095791), and to Bonnie Barber, Kathryn Modecki, and Jacquelynne Eccles (DP130104670). The authors would like to thank all high school principals, staff, and students who took part in the YAPS-WA study. They would also like to thank Kathryn Modecki and the contributors on the YAPS-WA project.

Citation: O’Donnell, A. W., \& Barber, B. L. (2020). Ongoing Engagement in Organized Activities May Buffer Disadvantaged Youth Against Increasing Externalizing Behaviors. Journal of Leisure Research.

https://doi.org/10.1080/00222216.2020.1741328

(C) 2020 National Recreation and Park Association 


\begin{abstract}
This study examined whether dropping out of non-sport organized activities predicted increased externalizing behaviors and if youth attending socioeconomically disadvantaged schools were disproportionately affected. Adolescents in Grade 8 who engaged in organized activities $(\mathrm{N}=$ $\left.418, \mathrm{M}_{\mathrm{T} 1}=13.46, \mathrm{SD}_{\mathrm{T} 1}=0.31\right)$ nominated the activity in which they spent the most time and were categorised as dropping out, swapping into a different activity, or remaining in that activity one year later. Multinominal logistic regression indicated that lower socioeconomic status (SES) predicted dropping out of activities compared to both swapping and remaining. Additionally, we found that dropping out of organized activities predicted increases in externalizing behaviors for adolescents who attended schools of lower or moderate SES. Conversely, there were no significant differences among participation statuses for adolescents in higher SES schools. These results provide evidence that socioeconomically disadvantaged youth are both the most likely to drop out and the most likely to benefit from continued participation in organized activities.
\end{abstract}

Keywords: disadvantaged adolescents, extracurricular activities, externalizing behaviors, organized activities, risk behaviors, socioeconomic status. 
Ongoing Engagement in Organized Activities May Buffer Disadvantaged Youth Against Increasing Externalizing Behaviors

School-related conduct problems, aggressive behaviors, and minor delinquencies, collectively known as externalizing behaviors, represent a key public health concern and typically increase during adolescence (Kim, 2018; Makarios, Cullen, \& Piquero, 2017; Moffitt, 1993). Although estimates of externalizing behaviors vary between studies, one multi-country investigation found that early adolescents, on average, reported engaging in one or more type of aggressive or risk-taking behavior (Duell et al., 2018). Subsequent increases in the types and variety of externalizing behaviors occur during adolescence, before typically reducing in adulthood (Duell et al., 2018; Monahan, Steinberg, Cauffman, \& Mulvey, 2009). Identifying contexts and experiences that protect adolescents from increasing rates of externalizing are therefore a high priority. Participation in organized, extracurricular activities during adolescence is a known protective factor for a range of negative developmental outcomes (Farb \& Matjasko, 2012). Both cross-sectional (Rose-Krasnor, Busseri, Willoughby \& Chalmers, 2006) and longitudinal studies (Busseri, Rose-Krasnor, Teena, \& Heather, 2006) have found that participating in organized activities during adolescence can defend against normative increases in externalizing behavior.

Although these results suggest a key protective role of activity participation, socioeconomically disadvantaged youth have less access to such opportunities (Heath, 2018) and are more prone to engaging in externalizing behaviors (Chang, Wang, \& Tsai, 2016) compared to more advantaged youth. Thus, the current study seeks to explore the complex interplay between socioeconomic status and continued participation in organized activities in predicting increases in externalizing behaviors in a sample of adolescents during their first two years of secondary school. In the following sections, we discuss the evidence demonstrating the protective impact of 
participation in organized activities, before highlighting the growing body of evidence

suggesting the benefits of activities may be most evident for those with fewest resources.

\section{Ongoing Organized Activity Involvement and Externalizing Behaviors}

Non-sporting organized activities offered in the extracurriculum encourage adolescents to pursue artistic, academic, vocational, service, and other specialized activities in structured and supervised settings outside the classroom ${ }^{1}$ (Mahoney, Larson, Eccles, \& Lord, 2005). The developmental outcomes associated with participating in organized activities have been extensively studied, with decades of research documenting the academic and psychosocial benefits for adolescent activity participants (e.g., Eccles \& Barber, 1999; Farb \& Matjesko, 2012; Fredricks \& Eccles, 2006). Important to the current study, participation in organized activities predicts lower externalizing behaviors, including physical aggression (Matjasko, Holland, Holt, Espelage, \& Koenig, 2019), substance use and delinquency (Kort-Butler, \& Martin, 2015; RoseKrasnor et al., 2006), and school conduct problems (Denault \& Dèry, 2015).

The positive outcomes associated with participating in organized activities are largely attributable to developmental assets and social capital that accrue through participation.

Organized activities are social contexts that place adolescents in regular and scheduled contact with supportive adults and peers who share interests and passions (Eccles, Barber, Stone, \& Hunt, 2003; Mahoney et al., 2005). Accordingly, the quality of the connections with, and the

\footnotetext{
${ }^{1}$ In this paper, we focus on non-sporting organized activities because organized sport activities are not as generally protective, and in fact have been linked to developmental risks and more antisocial behavior at times. Sport typically affords adolescents fewer developmental assets compared to non-sporting activities (Hansen, Larson, \& Dworkin, 2003), and can expose adolescents to deviant peers (e.g., Gardner, Roth, \& Brooks-Gunn, 2009; O’Donnell \& Barber, 2018) and antisocial climates (e.g., Spruit, Kavussanu, Smit, \& IJntema, 2019). Exposure to these risks may explain why sporting activities are less uniformly related to positive outcomes. Studies have linked sport participation to substance use (e.g., Modecki, Barber, \& Eccles, 2014; Wichstrom \& Wichstrom, 2009), externalizing behaviors (e.g., Kelley \& Sokol-Katz, 2011), and sexual aggression (e.g., Murnen \& Kohlman, 2007).
} 
behaviors modelled by, these supportive adults and peer groups can influence the behaviors of activity participants. Non-parental adults facilitating organized activities can provide advice, assistance, and model prosocial behaviors (Roth \& Brooks-Gunn, 2003), thereby contributing to the lower rates of externalizing among activity participants (Crean, 2012). Organized activities can also attract adolescents who are academically inclined, goal orientated, and involved in their community (Eccles et al., 2003; Fredricks \& Eccles, 2005). Longitudinal findings have demonstrated exposure to peers with these prosocial tendencies lead to positive outcomes during adolescence. In a study on urban youth, participation in organized activities led to positive connections with prosocial peers, which accounted for lower violent behavior and other risktaking behaviors among activity participants (Eisman, Lee, Hsieh, Stoddard, \& Zimmerman, 2018). Collectively, these studies demonstrate meaningful connections are vital to maximize the likelihood that organized activities will positively impact youth and ongoing activity involvement may be necessary to accrue such developmental assets.

In a comprehensive review, Bohnert, Fredricks and Randall (2010) discussed how duration, or enduring participation in organized activities over time, is an important indicator of activity involvement. Quality relationships can take years to form, and repeated practice over time is necessary to hone interpersonal and domain-specific skills that activity participation can foster (Bohnert et al., 2010). Alternative measures of activity participation, such as the number of different activities (i.e., breadth), can overlook these unfolding socialization and developmental processes despite their potential importance. Studies have illustrated how these unfolding processes can be important in defending against increasing externalizing behaviors. Ongoing participation in organized activities across adolescence has been positively related to meaningful connections, and subsequently more prosocial behaviors at the transition to adulthood (Viau, Denault, \& Poulin, 2015). Alternatively, declining participation, as indicated by transitions from 
high levels of participation to lower levels of participation over time, was associated with increases in externalizing behaviors (Agans et al., 2014).

These studies exemplify how ongoing engagement in organized activities can reduce externalizing behaviors, however participation continuity remains an understudied phenomenon. Moreover, the limited number of studies examining activity duration have largely neglected the nuanced distinction of ongoing organized activity duration in any activity, and the stability of participating in the same activity in the future (Bohnert et al., 2010). Longitudinal research is required to explore patterns of participation to provide a better understanding of the benefits of stability and the risks of instability.

The current study considers participation continuity in the same activity, ongoing involvement in any activity (i.e., swapping between activities), and dropping out of activities, to assess whether ongoing commitment over a longer period protects against normative increases in externalizing behaviors. The contextual constraints imposed by socioeconomic disadvantage are also considered as a backdrop to participation patterns. Accordingly, evidence indicating reduced levels of continued participation in organized activities for youth in low socioeconomic communities relative to those in more advantaged communities is reviewed next.

\section{The Interplay Between Developmental Needs and Opportunities to Participate in}

\section{Organized Activities}

Normative developmental processes ensure that rates of participation in organized activities typically decline over adolescence (Mahoney et al., 2005; Modecki, Blomfield Neira, $\&$ Barber, 2018). As adolescents mature, they develop a stronger sense of who they are, what they value, and they structure their time use to be more congruent with their emerging identity and interests (Fredricks et al., 2002). Consequently, motivation for and participation in organized activities may reflect current and changing developmental needs as young people search for 
meaning and develop identity, autonomy, competencies and social relations through participation (Fredricks et al., 2002; Simpkins, Fredricks, \& Eccles, 2012). Person-environment fit theories can guide this discussion, by considering the match between the attributes of the youth, including their identities and motivations, and the characteristics of the activities in which they participate (Eccles et al., 1993). The fit between adolescents' developmental needs and the experiences afforded by the activity are therefore important (Drane \& Barber, 2016; Modecki et al., 2018) and will predict both choice and persistence in activities (e.g., Eccles, Barber, \& Jozefowicz, 1998). When the activity does not fit the needs of participants, their motivation will decrease, and they may drop out of the organized activity or swap into an alternative activity that they perceive to be more suited to their interests and aptitudes.

Making individual decisions to reconfigure leisure time is thus common during adolescence, but it is important to acknowledge personal choices can be constrained by unequal distribution of opportunities. Accordingly, we draw upon ecological models of human development proposing that developmental processes can be influenced by environmental factors (Bronfenbrenner, 1995). Adopting this approach, we suggest adversities in macro-level settings can alter the prospects of remaining in organized activities, thereby constraining adolescents' agency when arranging and reconfiguring organized activities.

Community-level socioeconomic status can capture a wide-array of adversities or advantages concentrated or clustered within a specific area, including income, employment, family structure, education, and levels of public assistance (Leventhal \& Dupéré, 2019). Lower status, with accompanying adversities can include barriers restricting opportunities for stable engagement in organized activities (Morris, 2015; White \& Gager, 2007). Indeed, compared to advantaged students in high socioeconomic communities, disadvantaged students in low socioeconomic communities are significantly underrepresented in organized activities (Heath, 
2018; McNeal, 1998). Recent work has shown the disparity in participation rates across socioeconomic status has widened over the previous 25 years, further demonstrating the sustained inequality of access to organized activities (Meier, Hartmann, \& Larson, 2018). It is therefore apparent that participation in organized activities reflects an interplay between adolescents' motivation to engage and contextual constraints evident in the community (Anderson, Bohnert, \& Governale, 2018; Fredricks et al., 2002; Mahoney et al., 2005). As such, socioeconomic disadvantage could not only limit initial access, but also set in motion a process of quitting an activity, irrespective of the internal motivations and desires of the activity participant.

Adolescents in socioeconomically disadvantaged areas may have fewer opportunities to access organized activities for a variety of reasons. Low income families in these areas may not have the financial means to pay for activity-related expenses, as they impose a relatively larger financial burden on the family budget (An \& Western, 2019; Barber, Stone, \& Eccles, 2010). These expenses include direct costs of registration and equipment, in addition to ancillary costs associated with transportation and accommodations of parental work schedules to facilitate participation (Dearing et al., 2009; Lareau \& Weininger, 2008; Weininger, Lareau, \& Conley, 2015).

Beyond family-specific factors, community-level socioeconomic disadvantage can impede ongoing participation in organized activities because fewer activities are offered (Stearns \& Glennie, 2010). Adolescents in disadvantaged communities with interests and aptitudes aligned to a specific activity may not find that specific activity offered (Bennett, Lutz, \& Jayaram, 2012). Furthermore, families in socioeconomically disadvantaged communities often report lower levels of neighborhood cohesion (An \& Western, 2019). In turn, families in less cohesive communities may not share information about the type and location of different 
activities and do not share the burden (e.g., car-pooling), decreasing the already limited capacity for families to facilitate ongoing participation (An \& Western, 2019). These effects of community-level disadvantage on participation rates emerge even after controlling for familyincome (An \& Western, 2019), suggesting a broad array of contextual constraints can reduce opportunities to engage in organized activities.

Collectively, these issues present barriers to initial engagement in organized activities, limit opportunities to switch between enriching activities, and can make continued participation difficult for activity participants in socioeconomically disadvantaged areas. The barriers preventing socioeconomically disadvantaged youth from continued immersion in positive developmental contexts, like structured organized activities, is particularly problematic when considering that socioeconomic disadvantage is also a significant risk factor for externalizing behaviors. Thus, protective experiences afforded during organized activity participation that can reduce risk factors for externalizing are less available to those who are most vulnerable. Next, we review these risk factors and provide evidence that benefits from activity participation are especially salient for youth in socioeconomically disadvantaged communities.

\section{Who Benefits from Activities and Why? Socioeconomic Status and Externalizing}

\section{Behaviors.}

Recent meta-analytic evidence concluded socioeconomic disadvantage during adolescence was reliably related to higher levels of externalizing behaviors (Chang et al., 2016; Piotrowska, Stride, Croft, \& Rowe, 2015). A key factor predicting more positive outcomes for adolescents is the availability of community-wide developmental resources. Adolescents who reside, learn, and play in advantaged neighborhoods are afforded a range of resources that promote healthy developmental outcomes. Advantaged adolescents often have access to supervised peer interactions, supportive adult figures, and exposure to a safe environment 
(Leventhal \& Brooks-Gunn, 2000). In contrast, adolescents in disadvantaged communities have fewer opportunities to access to these same supportive and safe interactions developmental assets (Magson, Craven, Munns, \& Yeung, 2016; Leventhal \& Brooks-Gunn, 2000). Increased externalizing behaviors amongst disadvantaged youth is linked to both fewer and lower quality social connections (Fergusson, Swain-Campbell, \& Horwood, 2004; Magson et al., 2016). Therefore, supporting opportunities for disadvantaged youth to access spaces that encourage positive development and constructive experiences with the people around them could foster well-being and reduce the prevalence of externalizing behaviors.

Participation in organized activities could expose youth to positive developmental resources and social capital through positive adult role models and prosocial peers (Fredricks \& Eccles, 2005; White \& Gager, 2007). Fostering these positive networks can be particularly salient for adolescents in socioeconomically disadvantaged areas because they have fewer opportunities to associate with institutionally connected adults and highly motivated peers (Morris, 2015). In contrast, youth in more advantaged communities have more positive developmental assets in a variety of other extrafamilial contexts, such as more supportive institutions and less risky peers (Leventhal \& Dupéré, 2019). For adolescents in communities with high socioeconomic status, the availability of these positive developmental resources diminishes the impact of similar experiences (e.g., forming meaningful connections) during activity participation (Morris, 2015). Consequently, organized activity participation can offer greater benefits to disadvantaged adolescents relative to their more advantaged peers by compensating for more limited developmental resources (Morris, 2015; Stanton-Salazar, 2011).

A growing number of studies supports the notion that disadvantaged youth are particularly likely to benefit from involvement in organized activities, relative to advantaged adolescents. For example, there is a more positive association between activity participation and 
general self-worth for adolescents from disadvantaged schools compared to those in more advantaged schools (Blomfield \& Barber, 2011). Similar findings have also been observed with social (Steinberg \& Simon, 2019) and academic outcomes (Crosnoe, Smith, \& Leventhal, 2015; Tommaso \& Longobardi, 2017). With specific reference to externalizing behaviors, adolescents identified as being at risk were less likely to drop out of school (Mahoney \& Cairns, 1997) and less likely to be arrested as young adults (Mahoney, 2000) if they participated in organized activities. In contrast, adolescents included in these samples not classified at-risk exhibited few problem behaviors irrespective of involvement in organized activities (Mahoney, 2000; Mahoney \& Cairns, 1997). Taken together, these findings illustrate that vulnerable adolescents who engage in organized activities have better outcomes compared to non-participating vulnerable adolescents and that the advantages of participating in organized activities may be less developmentally facilitative for advantaged youth. However, as previously noted, vulnerable adolescents have more barriers preventing their continued participation in organized activities, and the impact of dropping out of this protective environment is not well understood for this group.

\section{The Current Study}

The aims of the current study are to determine if youth attending socioeconomically disadvantaged schools have less stability in their rates of activity participation compared to more socioeconomically advantaged youth. Additionally, the study aimed to examine if changing participation status from the first year of secondary school to the second predicts changes in levels of externalizing behaviors, and to test whether youth in disadvantaged communities are disproportionately affected. By addressing these aims, the current study will expand upon previous research by examining both the likelihood and impact of withdrawing from organized activity contexts. In accordance with the aims of the study, several hypotheses were tested. First, 
we predicted that adolescents who attended socioeconomically disadvantaged schools would be more likely to drop out of organized activities compared to both remaining in and swapping between activities. Second, congruent with meta-analytic findings (Piotrowska et al., 2015), socioeconomic advantage was expected to be related to lower externalizing behaviors. Third, it was expected that adolescents who dropped out of organized activities would report greater increase in their externalizing behaviors compared to adolescents who continued to participate. Finally, socioeconomic status was predicted to exacerbate the effect of dropping out of organized activities, whereby, adolescents who dropped out of organized activities would report higher externalizing behaviors if they also attended socioeconomically disadvantaged schools.

\section{Method}

\section{Participants and Procedure}

Grade 8 students were invited to participate in an annual survey of leisure time pursuits as part of a larger longitudinal project conducted in Western Australia (Youth Activity Participation Study). Parental consent was obtained for 1,099 participants at the first time point. The data included in the current study were from participants who completed the first (T1, Grade 8) and second (T2, Grade 9) waves of data collection $\left(\mathrm{N}=890 ; 59.1 \%\right.$ female; Age: $\mathrm{M}_{\mathrm{T} 1}=13.46$, $\left.\mathrm{SD}_{\mathrm{T} 1}=0.31, \mathrm{M}_{\mathrm{T} 2}=14.40, \mathrm{SD}_{\mathrm{T} 2}=0.30\right)$. The students were recruited from 29 high schools selected using a stratified method to ensure representation across 9 school districts in Western Australia. The number and type of schools approached to participate in this project were selected based upon student enrollments in each district to ensure representation across public (48.3\%) and private (51.7\%) schools in metropolitan (63.1\%) and regional (36.9\%) school districts. Researchers administered the survey at school, typically in the third school term (JulySeptember). Survey completion took approximately 45 minutes during a classroom session via laptops or paper-and-pen. The second wave of data collection used the same procedure and was 
conducted the following year, generally during the same school term as the initial wave of data collection. The study had ethical approval from the [information blinded for peer review].

\section{Measures}

Activity Status. Participants were provided with a list of popular Australian non-sport organized activities with options to add activities not listed. Participants reported if they engaged in any activities at school outside of class or in the community within the school year and estimated the number of hours per week they spent in each activity. Participants then selfnominated a target activity, in which they spent the most time (i.e., "If you have circled any nonsporting activities please tell us which one you spend the most time in."). The analyses included participants who had engaged in an organized activity at the first time point and nominated their target activity $(N=418)$. For these participants, musical instrument $(21.5 \%)$, dance $(16.3 \%)$, and musical theatre $(6.0 \%)$ were the most popular target activities, but there were a range of target activities (e.g., defense force cadets, 5.0\%; service work, 1.7\%). Participants only selected the one target activity that spent the most time in. On average, the participants reported spending 3.0 $(S D=3.01)$ hours in their target activity each week during Grade 8.

Activity status was determined after participants responded to the same inventory approximately 12 months later. At the second time point, participants who indicated they did not spend time in any organized activity were coded as dropping out (21.9\%). Participants who continued to engage in organized activities but no longer participated in the target activity from the previous year were coded as having swapped (26.5\%) and participants who reported continued participation in their target activity were coded as having remained (51.6\%).

Externalizing Behaviors. Participants were asked to nominate how frequently they engaged in 8 types of externalizing behaviors during the previous 6 months on an 8 point scale ( 1 $=$ none, $2=$ once, $3=2-3$ times, $4=4-6$ times, $5=7-10$ times, $6=11-20$ times, $7=21-30$ 
times, $8=31$ or more times). The complete list of behaviors included skipping school, engaging in dangerous behaviors, doing risky things, damaging public property, being in contact with the police, getting in physical fights, taking something from a store without paying, and stealing money. The scale was adapted from previous research (Fredricks \& Eccles, 2005) and has been used in a range of studies (e.g., Author citation removed). Across both time points, the scale was internally consistent (Time 1: $\alpha=.80$; Time $2: \alpha=.87$ ).

Socioeconomic Status. School-level socioeconomic environment information was sourced from Australian Curriculum, Assessment and Reporting Authority (ACARA), using the Index of Community Socio-Educational Advantage (ICSEA). A school's score includes averaged information about the income, ethnicity, occupation, and education for each student's household as well as school factors including number of indigenous students and geographic location (ACARA, 2010). The ICSEA is standardized to have a mean of 1,000 and a standard deviation of 100 to reflect socioeconomic status, but in this instance, was converted to have a mean of 10 and a standard deviation of 1 . Higher scores denote higher socioeconomic status.

\section{Analytical Strategy}

Initially, bivariate correlations and descriptive statistics were calculated. Subsequently, the data were analyzed in two steps. First, a multinomial logistic regression was conducted with activity status at Time 2 as the outcome variable to explore whether socioeconomic disadvantage at Time 1 predicts stability and change in non-sport activity participation. Second, a regression analysis was conducted using the PROCESS macro in SPSS (Hayes, 2013) to examine if (1) participants who dropped out of activities reported greater increases in externalizing behaviors compared to participants who swapped or remained, and (2) if the difference was moderated by socioeconomic status at Time 1 . To predict changes in externalizing behaviors over time, externalizing behaviors at Time 1 was entered as a covariate in the regression model. Therefore, 
the remaining variance in externalizing behavior at Time 2 represents the change in responses between the two measurements (Kenny, 1975). In both analyses, participants who dropped out of organized activities were the reference group. ${ }^{2}$ Gender was added as a covariate $(0=$ Female, $1=$ Male).

\section{Results}

\section{Bivariate Correlations and Descriptive Statistics}

There were several significant bivariate correlations (Table 1), albeit with small effect sizes. Specifically, socioeconomic status was significantly related to externalizing behaviors (T2), whereby participants from more socioeconomically advantaged schools reported lower externalizing behaviors. Additionally, boys reported significantly higher externalizing behaviors at both time points compared to girls.

\section{Predictors of Activity Status}

Activity status was the outcome variable in a logistic regression analysis (Negelkerke $R^{2}$ $=.06)$. The drop-out category was the reference group. The goodness-of-fit test indicated that the model fit well $\left(\chi^{2}[352]=391.83, p=.070\right)$. Additionally, a log likelihood comparison revealed that the inclusion of the predictor variables in the model improved the model fit in comparison to the intercept only model $\left(\chi^{2}[6]=21.33, p=.002\right)$. The results for individual predictor variables (Table 2) indicate that adolescents who attended more socioeconomically advantaged schools were significantly more likely to remain in, or swap out of, their activity than drop out, in comparison to more disadvantaged youth. Odds ratio revealed that for everyone standard

${ }^{2}$ Follow up analyses were conducted with participants who remained in their target activity as the reference group. These analyses were conducted to compare participants who dropped out and those who swapped. In all cases, there were no significant differences between these two groups. 
deviation increase in socioeconomic status, the odds of remaining or swapping in an activity increased by $51.2 \%$ and $63.0 \%$ respectively, compared to dropping out of non-sport organized activities. Time 1 externalizing behaviors did not significantly predict participation status.

\section{Predictors of Externalizing Behaviors}

At the first step of the analysis, externalizing behaviors at Time 1, socioeconomic status, pubertal timing, gender, and activity status were entered as predictor variables. Activity status was treated as a multi-categorical independent variable by recoding it into two dummy coded variables (Jose, 2016). The first (D $\mathrm{D}_{\text {Swap }}$ ) provided a comparison between participants who dropped out of their activity and those who swapped, and the second ( $D_{\text {Remain }}$ ) provided a comparison between participants who dropped out and continued their participation in the same activity. At the second step of the analysis, the interaction between the multi-categorical comparisons and socioeconomic status were simultaneously entered into the model. The model results, including the unstandardized and standardized regression coefficients, and the variance explained (semi-partial correlation, $s r^{2}$ ) are included in Table $3 .{ }^{3}$ The interaction was then probed using the pick-a-point procedure described in Hayes and Montoya (2017). This procedure allowed an investigation of the strength and significance of the difference between the drop out category and both swap ( $\left.\mathrm{D}_{\text {Swap }}\right)$ and remain $\left(\mathrm{D}_{\text {Remain }}\right)$ respectively. This common technique involves selecting values to represent the moderating variable (e.g., low, moderate, and high) and examining the conditional effect of the independent variable on the outcome at those distinct

\footnotetext{
${ }^{3}$ Multiple regression is an analytical technique robust to non-normal data (Tabachnick \& Fidell, 2013). Nevertheless, externalizing behaviors at T1 and T2 were positively skewed. To ensure the results were not biased by the inclusion of these skewed variables, an additional analysis was conducted after attempts to normalize the date with logarithmic transformations. The direction and significance of all main effects, interaction terms, and the subsequent probing of interactions using the 'pick-a-point' technique, were consistent with the untransformed measures reported in text.
} 
values (Hayes \& Matthes, 2009). Lower socioeconomic status was computed as one standard deviation below the mean, moderate socioeconomic status was the mean, and higher socioeconomic status was computed one standard deviation above the mean.

At step one of the regression analysis (Table 3), $31 \%$ of the variance in externalizing behaviors (T2) was explained by the combination of predictor variables $(F[5,382]=33.80, p$ $<.001)$. The significant relationship between externalizing behaviors at Time 1 with externalizing behaviors at Time 2 indicates some stability in responses over time. Socioeconomic status was significantly associated with externalizing behaviors at time two, with more advantaged socioeconomic status related to less externalizing behaviors. Additionally, the two multi-categorical comparisons indicated that participants who dropped out of their organized activities reported significantly higher externalizing behaviors compared to those who swapped (Dswap) and those who continued their participation ( $D_{\text {Remain }}$. Gender was not significantly and uniquely related to the residualized externalizing behavior.

At the second step of the analysis, the inclusion of the two interaction terms resulted in a significant increase in the amount of variance explained in externalizing behaviors $\left(\mathrm{R}^{2}\right.$ chg $=.02$, $F[2,380]=4.57, p=.011)$. Further probing of the interaction with the 'pick-a-point' technique was conducted (Figure 1). This analysis revealed that the difference in externalizing behaviors between participants who dropped out of organized activities and continued in some form (swap and remain) was conditional upon the socioeconomic context of the adolescents. At lower levels of socioeconomic status, the test of equality of conditional means was significant $\left(\mathrm{R}^{2 \mathrm{chg}}=.05, p\right.$ $<.001)$. Participants who dropped out of organized activities reported significantly higher externalizing behaviors compared to participants who swapped activities (Dswap: $B=-.51, p$ $<.001)$ or remained ( $\left.D_{\text {Remain }} \mathrm{B}=-.48, \mathrm{p}<.001\right)$. Similarly, there were significant differences at moderate levels of socioeconomic status $\left(\mathrm{R}^{2}\right.$ chg $\left.=.02, p=.005\right)$ with externalizing behaviors 
lower for participants who swapped ( $\mathrm{D}_{\text {Swap }}: B=-.27, p=.003$ ) or remained in their organized activity (Demain: $B=-.25, p=.003$ ) compared to those who dropped out. In contrast, there was no significance difference in the equality of means between the three activity statuses for the participants attending schools of higher socioeconomic status $\left(\mathrm{R}^{2}\right.$ chg $\left.<.01, p=.974\right) .{ }^{4}$

\section{Discussion}

The current study addressed several aims: (1) examine the role of socioeconomic disadvantage in changes in non-sport activity participation, (2) determine if dropping out of organized non-sport activities predicted increases in externalizing behaviors, and (3) examine if youth attending socioeconomically disadvantaged schools reported greater externalizing behaviors following shifts away from participation. To address these aims, we tested four hypotheses in a sample of adolescents who were involved in organized activities during their first year of secondary school. All four hypotheses, discussed below, were supported.

\section{Results and their Implications}

First, lower socioeconomic status predicted higher likelihood of dropping out of organized activities one year later compared to both remaining in an activity or swapping into a new one. Students in more advantaged schools experienced greater stability from Grade 8 to Grade 9 in their activity participation than their peers attending more socioeconomically disadvantaged schools. Addressing this disparity in continued participation will require a multifaceted approach that target issues at both the community and family level. When

\footnotetext{
${ }^{4}$ Further analyses were conducted to test the robustness of the pick-a-point technique. In this supplementary analysis, low, moderate, and high levels of socioeconomic status were the $25^{\text {th }}, 50^{\text {th }}$, and $75^{\text {th }}$ percentile of the continuous socioeconomic status variable. The tests of equality of conditional means produced effects with the same significance and direction as the coefficients reported in text (i.e., using standard deviations as the cut-off criteria).
} 
considering those who shift their participation, socioeconomically advantaged adolescents may be afforded a higher level of inter-activity mobility when they choose or are compelled to quit a specific organized activity. Previous research has demonstrated that socioeconomically advantaged communities generally offer more organized activities (Cohen et al., 2007). With more opportunities on offer, youth in these advantaged communities have greater mobility allowing them to substitute alternative activities more easily than adolescents in disadvantaged communities when a primary activity loses its appeal or becomes too challenging or impractical.

Our data are consistent with calls for greater provision of opportunities for young people in disadvantaged schools. This need is supported by evidence that schools offering more activities report better outcomes irrespective of the affluence of the school (Stearns \& Glennie, 2010). However, family socioeconomic disadvantage can also impede participation in organized activities. The registration and ancillary expenses associated with activity participation carry a proportionately larger impact on the family budget for low-income families (Barber et al., 2010; Weininger et al., 2015). The reality is that budget cuts in education may result in school band and debating club being placed on the chopping block - but replacing such activities with attractive alternatives is more difficult for resource-limited families. Schools, clubs, and organizations could assist lower-income families by offering disadvantaged adolescents subsidized participation and equipment, including access to musical instruments, dance costumes, or art supplies.

Second, the significant negative relationship between Time 1 socioeconomic status and Time 2 externalizing behaviors is consistent with previous meta-analytic evidence linking socioeconomic disadvantage and risk-taking behaviors (Piotrowska et al., 2015). With Time 1 externalizing controlled, increases in externalizing were greater among adolescents attending more socioeconomically disadvantaged schools. Although expected, this finding reinforces the 
importance of identifying settings that can ameliorate the otherwise negative effects of disadvantage. Previous research has found that organized activities are a protective space (e.g., Mahoney, 2000), and the current study added to this literature by focusing on the extent of that protection in general, and specifically for more disadvantaged students. The next two hypotheses focus on these findings.

Participants who dropped out of organized activities reported significantly greater increases in externalizing behaviors compared to adolescents who either remained in their activity or swapped into a new one. This finding is notable, particularly given the overall pattern of results that indicated relatively low rates of externalizing over the two years. As expected during early adolescence, externalizing behaviors were not generally high or dramatically increasing (Duell et al., 2018). However, where changes in externalizing behaviors were observed, they were predicted by shifts away from organized activities. This finding builds upon previous research showing that participation in organized activities across adolescence is predictive of lower externalizing behaviors (Busseri et al., 2006) by specifically assessing the difference between continued participation and withdrawing from a known protective environment (Bohnert et al., 2010). Further, the benefits of participation are also evident for those who swap into a new activity. Both remaining in the same activity and swapping to something else offer protection, relative to dropping out of an activity without a replacement to fill its place.

Finally, we found that adolescents attending socioeconomically disadvantaged schools were disproportionality at risk of engaging in increased externalizing behaviors if they discontinued their activity, compared to remaining or shifting to another activity. This significant result also held for adolescents in schools of moderate socioeconomic status. There were no significant differences between participants who dropped out, swapped, or remained in their 
activity for participants who attended socioeconomically advantaged schools. The results indicate that continued organized activity participation (whether in the same or different activity) can be beneficial for adolescents and dropping out of organized activities appears particularly problematic for disadvantaged youth. In contrast, youth in high socioeconomic communities were protected from the ill-effects of dropping out of organized activities.

These results are congruent with claims that the beneficial experiences and extrafamilial connections acquired through organized activities are compensatory in disadvantaged contexts, where such experiences may be more limited (Blomfield \& Barber, 2011; Morris, 2015). However, the current study also demonstrated the positive effects associated with continued involvement in organized activities were not limited to adolescents in the most disadvantaged communities. The significant findings at moderate levels of socioeconomic status are indicative of the generally protective role of organized activities and are congruent with the large literature demonstrating that youth who participate in these activities report fewer externalizing behaviors (e.g., Denault \& Dèry, 2015). Indeed, it is apparent from the current research that most adolescents stand to benefit from activity participation. It is only in more advantaged contexts where youth can readily tap into a broader milieu characterized by a wider range of supportive and prosocial connections where the provision of positive experiences through organized leisure pursuits may be less essential in protecting against externalizing behaviors (Blomfield \& Barber, 2011).

Taken together, these findings highlight that adolescents attending socioeconomically disadvantaged schools are at a higher risk of engaging in problematic behaviors than their more advantaged counterparts, but that risk is mitigated through continued participation in structured, non-sport, organized activities. Despite the clear benefits of participation for this at-risk group, adolescents attending socioeconomically disadvantaged schools are also at a higher risk of 
dropping out of their activities and thereby removing themselves from a protective environment that provides developmental resources and fosters key capabilities and connections. The increased vulnerability of young people learning in disadvantaged schools to risk-taking through externalizing is a cause for concern, particularly as there are known sanctuaries that can nurture and support disadvantaged young people (Heath et al., 2018; McLaughlin, Irby, \& Langman, 1994). Consistent with the work of McLaughlin and her colleagues, we demonstrated that organized activities in the school and in the community represent such a sanctuary. Building greater public will to create opportunities, and supporting adolescent and family access to them, is essential for facilitation of healthy development among those with more limited social resources.

\section{Limitations and Conclusion}

As with all longitudinal survey research, there are some limitations with these data. Causal conclusions are not possible. The temporal ordering is uncertain, given that increases in externalizing may have resulted in subsequent disconnection from previously favored activities. However, in support of the proposed direction of effect from dropping out to externalizing increases, initial externalizing behaviors did not significantly predict the likelihood of dropping out of activities one year later. This result does not, however, rule out that other more substantial changes in family situation or peer group might precede or co-occur with dropping out of an activity, at least partially accounting for increased externalizing. In fact, it seems likely that for disadvantaged young people, more volatile social contexts impinge on their opportunities for, and barriers to, arenas of extracurricular participation that can foster optimal development. As we have demonstrated, that carries a potential cost in terms of risk to wellbeing.

Notwithstanding the limitations, we have displayed the protective role of continued activity participation that is particularly salient for youth learning in disadvantaged 
environments. In particular, our findings offer insight into how young people who benefit the most from continued activity participation are the same young people who are most at risk of withdrawing. Identifying adolescents at risk of engaging in externalizing behaviors due to socioeconomic disadvantage, providing them with opportunities for a range of good quality activity participation settings, and encouraging them to continue to engage in organized activities could prove instrumental in reducing their engagement in problematic behaviors during adolescence. 


\section{References}

Agans, J. P., Champine, R., DeSouza, L. M., Mueller, M. K., Johnson, S., \& Lerner, R. M. (2014). Activity involvement as an ecological asset: Profiles of participation and youth outcomes. Journal of Youth \& Adolescence, 43, 919-932. Doi: 10.1007/s10964-014-0091-1

An, W., \& Western, B. (2019). Social capital in the creation of cultural capital: Family structure, neighborhood cohesion, and extracurricular participation. Social Science Research, 81, 192-208. Doi: 10.1016/j.ssresearch.2019.03.015

Anderson, N.A., Bohnert, A.M. \& Governale, A. (2018). Organized activity involvement among urban youth: understanding family- and neighborhood- level characteristics as predictors of involvement. Journal of Youth \& Adolescence, 47, 1697-1711. Doi: 10.1007/s10964-018$0823-8$

Australian Curriculum, Assessment and Reporting Authority (ACARA). (2010). My school technical paper. Sydney, NSW: ACARA.

Barber, B. L., Stone, M. R., \& Eccles, J. S. (2010). Protect, prepare, support, and engage: The roles of school-based extracurricular activities in students' development. In J. L. Meece \& J. S. Eccles (Eds.), Handbook of research on schools, schooling, and human development (pp. 366-378). New York, NY: Routledge.

Bennett, P. R., Lutz, A. C., \& Jayaram, L. (2012). Beyond the schoolyard: the role of parenting logics, financial resources, and social institutions in the social class gap in structured activity participation. Sociology of Education, 85, 131-157. Doi:

$10.1177 / 0038040711431585$

Blomfield, C. \& Barber, B. (2010). Australian adolescents' extracurricular activity participation and positive development: Is the relationship mediated by peer attributes? Australian Journal of Educational \& Developmental Psychology, 10, 114-128. 
Blomfield, C. J., \& Barber, B. L. (2011). Developmental experiences during extracurricular activities and Australian adolescents' self-concept: Particularly important for youth from disadvantaged schools. Journal of Youth and Adolescence, 40, 582-594. doi:10.1007/s10964-010-9563-0

Bohnert, A., Fredricks J., \& Randall, E. (2010). Capturing unique dimensions of youth organized activity involvement: theoretical and methodological considerations. Review of Educational Research, 80, 576-610. Doi: 10.3102/0034654310364533

Brody, G. H., Ge, X., Conger, R., Gibbons, F., Murry, V. M., Gerrard, M., \& Simons, R. L. (2001). The Influence of neighborhood disadvantage, collective socialization, and parenting on African American children's affiliation with deviant peers. Child Development, 72, 1231-1246.

Bronfenbrenner, U. (1995). Developmental ecology through space and time: A future perspective. In P. Moen, G. Elder, \& K. Luscher (Eds.), Examining lives in context: Perspectives on the ecology of human development (pp. 619-647, Washington D.C: USA. Doi: $10.1037 / 10176-018$

Busseri, M. A., Rose-Krasnor, L., Willoughby, T., \& Chalmers, H. (2006). A longitudinal examination of breadth and intensity of youth activity involvement and successful development. Developmental Psychology, 42, 1313-1326. doi: 10.1037/00121649.42.6.1313

Chang, L., Wang, M., \& Tsai, P. (2016). Neighborhood disadvantage and physical aggression in children and adolescents: A systematic review and meta-analysis of multilevel studies. Aggressive Behavior, 42, 441-454. Doi: 10.1002/ab.21641 
Cohen, D. A., Taylor, S. L., Zonta, M., Vestel, K. D., \& Schuster, M. A. (2007). Availability of high school extracurricular sports programs and high-risk behaviors. Journal of School Health, 77, 80-86. doi: 10.1111/j.1746-1561.2007.00171.x

Crean, H. F. (2012). Youth activity involvement, neighborhood adult support, individual decision making skills, and early adolescent delinquent behaviors: Testing a conceptual model. Journal of Applied Developmental Psychology, 33, 175-188. Doi:

10.1016/j.appdev.2012.04.003

Crosnoe, R., Smith, C., \& Levanthal, T. (2015). Family Background, School-Age Trajectories of Activity Participation, and Academic Achievement at the Start of High School. Applied Developmental Science, 19, 139-152. Doi: 10.1080/10888691.2014.983031

Dearing, E., Wimer, C., Simpkins, S. D., Lund, T., Bouffard, S. M., Caronongan, P., ... \& Weiss, H. (2009). Do neighborhood and home contexts help explain why low-income children miss opportunities to participate in activities outside of school? Developmental Psychology, 46, 1545-1562. Doi: 10.1037/a0017359

Denault, A., \& Dèry, M. (2015). Participation in organized activities and conduct problems in elementary school: the mediating effect of social skills. Journal of Emotional and Behavioural Disorders, 23, 167-179. Doi: 10.1177/1063426614543950

Drane, C. F., \& Barber, B. L. (2016). Who gets more out of sport? The role of value and perceived ability in flow and identity-related experiences in adolescent sport. Applied Developmental Science, 20, 267-277. doi: 10.1080/10888691.2015.1114889

Duell, N., Steinberh, L., Icenogle, G., Chein, J., Chaudhary, N., Di Giunta, L., ... Chang, L. (2018). Age patterns in risk taking across the world. Journal of Youth \& Adolescence, 47, 1052-1072. Doi: 10.1007/s10964-017-0752-y 
Eccles, J. S., Midgley, C., Wigfield, A., Buchanan, C. M., Reuman, D., Flanagan, C., \& MacIver, D. (1993). Development during adolescence: The impact of stage-environment fit on adolescents' experiences in schools and families. American Psychologist, 48, 90-101. doi:10.1037/0003-066x.48.2.90

Eccles, J. S., Barber, B. L., \& Jozefowicz, D. (1998). Linking gender to educational, occupational, and recreational choices: Applying the Eccles et al. model of achievementrelated choices. W. B. Swann, J. H. Langlois, \& L. C. Gilbert (Eds.) Sexism and stereotypes in modern society: The gender science of Janet Taylor Spence (pp. 153192). Washington DC: American Psychological Association.

Eccles, S. E., Barber, B. L., Stone, M., \& Hunt, J. (2003). Extracurricular activities and adolescent development. Journal of Social Issues, 59, 865-889. doi: 10.1046/j.00224537.2003.00095.x

Eisman, A. B., Lee, D. B., Hsieh, H., Stoddard, S. A., \& Zimmerman, M. A. (2018). More Than Just Keeping Busy: The Protective Effects of Organized Activity Participation on Violence and Substance Use Among Urban Youth. Journal of Youth \& Adolescence, 47, 2231-2242. Doi: $10.1007 / \mathrm{s} 10964-018-0868-8$

Farb, A. F. \& Matjasko, J. (2012). Recent advances in research on school-based extracurricular activities and adolescent development. Developmental Review, 32, 1-48. doi: 10.1016/j.dr.2011.10.001

Fergusson, D., Swain-Campbell, N. R., \& Horwood, J. (2004). How does economic disadvantage lead to crime. Journal of Child Psychology and Psychiatry, 47, 956-966. doi: 10.1111/j.1469-7610.2004.t01-1-00288.x 
Fredrick, J. A., Alfred-Liro, C. J., Hruda, L. Z., Eccles, J. S., Patrick, H., \& Ryan, A. M. (2002). A qualitative exploration of adolescents' commitment to athletics and the arts. Journal of Adolescent Research, 17, 68-97. Doi: 10.1177/0743558402171004

Fredricks, J. A., \& Eccles, J. S. (2005). Developmental benefits of extracurricular involvement: Do peer characteristics mediate the link between activities and youth outcomes? Journal of Youth and Adolescence, 34, 504-520. doi: 10.1007/s10964-005-8933-5

Fredricks, J. A., \& Eccles, J. S. (2006). Is extracurricular participation associated with benefical outcomes? Current and longitudinal relations. Developmental Psychology, 42, 698-713. doi: $10.1037 / 0012-1649.42 .4 .698$.

Gardner, M., Roth, J., \& Brooks-Gunn, J. (2009). Sports participation and juvenile delinquency: the role of the peer context among adolescent boys and girls with varied histories of problem behavior. Developmental Psychology, 45, 341-353. Doi: 10.1037/a0014063

Hansen, D., Larson, R., \& Dworkin, J. (2003). What adolescents learn in organized youth activities: A survey of self-reported developmental experiences. Journal of Research on Adolescence, 13, 25-55. doi: 10.1111/1532-7795.1301006

Hayes, A. F. (2013). Introduction to mediation, moderation, and conditional process analysis. New York, USA: The Guilford Press.

Hayes, A. F., \& Matthes, J. (2009). Computational procedures for probing interactions in OLS and logistic regression: SPSS and SAS implementations. Behavior Research Methods, 41, 924-936. doi: 10.3758/BRM.41.3.924

Hayes, A. F., \& Montoya, A. K. (2017) A tutorial on testing, visualizing, and probing an interaction involving a multicategorical variable in linear regression analysis.

Communication Methods and Measures, 11, 1-30. doi: 10.1080/19312458.2016.1271116 
Heath, R. D., Anderson, C., Turner, A. C., \& Payne, C. M. (2018). Extracurricular Activities and Disadvantaged Youth: A Complicated — But Promising-Story. Urban Education, 1-35. Doi: $10.1177 / 0042085918805797$

Jose, P. E. (2013). Doing Statistical Mediation \& Moderation. The Guilford Press: New York.

Kelley, M. S., \& Sokol-Katz, J. (2011). Examining participation in school sports and patterns of delinquency using the National Longitudinal Study of Adolescent Health. Sociological Focus, 44, 81-101. Doi: 10.1080/00380237.2011.10571389

Kenny, D. A. (1975). Cross-Lagged panel correlation: A test for spuriousness. Psychological Bulletin, 82, 887-903.

Kim, J. (2018). The role of violent and nonviolent delinquent behavior in educational attainment. Youth \& Society, 1-26. Doi: 10.1177/0044118X18781641

Kort-Butler, L. A., \& Martin, D. D. (2015). The Influence of High School Activity Portfolios on Risky Behaviors in Emerging Adulthood. Justice Quarterly, 32, 381-409. Doi: $10.1080 / 07418825.2013 .770547$

Lareau, A., \& Weininger, E. B. (2008). Time, work, and family life: reconceptualizing gendered time patterns through the case of children's organized activities. Sociological Forum, 23, 419-454. Doi: 10.1111/j.1573-7861.2008.00085.x

Leventhal, T., \& Brooks-Gunn, J. (2000). The neighborhoods they live in: the effects of neighborhood residence on child and adolescent outcomes. Psychological Bulletin, 126, 309-337. doi: 10.1037/0033-2909.126.2.309

Leventhal, T., Dupéré, V. (2019). Neighborhood Effects on Children's Development in Experimental and Nonexperimental Research. Annual Review of Developmental Psychology, 1, 149-176. Doi: 10.1146/annurev-devpsych-121318-085221 
Magson, N. R., Craven, R. G., Munns, G., \& Yeung, A. S. (2016). It is risky business: can social capital reduce risk-taking behaviors among disadvantaged youth? Journal of Youth Studies, 19, 569-592. doi: 10.1080/13676261.2015.1098776

Mahoney, J. L. (2000). School extracurricular activity participation as a moderator in the development of antisocial patterns. Child Development, 71, 502-516. doi:10.1111/14678624.00160

Mahoney, J. L., \& Cairns, R. B. (1997). Do extracurricular activities protect against early school dropout? Developmental Psychology, 33, 241-253. doi: 10.1037/0012-1649.33.2.241

Mahoney, J. L., Larson, R. W., Eccles, J. S., \& Lord, H. (2005). Organized activities as developmental contexts for children and adolescents. In J. L. Mahoney, R. W. Larson, \& J. S. Eccles (Eds.) Organized Activities as Contexts of Development: Extracurricular activities, after-school, and community programs. Lawrence Erlbaum Associates: New Jersey.

Makarios, M., Cullen, F. T., \& Piquero, A. R. (2017). Adolescent criminal behavior, population heterogeneity, and cumulative disadvantage: untangling the relationship between adolescent delinquency and negative outcomes in emerging adulthood. Crime \& Delinquency, 63, 683-707. Doi: 10.1177/0011128715572094

Marsh, H. W., \& Kleitman, S. (2002). Extracurricular school activities: The good, the bad, and the nonlinear. Harvard Educational Review, 72, 464-511.

Matjasko, J. L., Holland, K. M., Holt, M., Espelage, D. L., \& Koenig, B. W. (2019). All things in moderation? Threshold effects in adolescent extracurricular participation intensity and behavioral problems. Journal of School Health, 89, 79-87. Doi: 10.1111/josh.12715

McLaughlin, M. W., Irby, M. A., \& Langman, J. (1994). Urban Sanctuaries: Neighborhood organizations in the lives and futures of inner-city youth. Jossey-Bass Inc: San Francisco. 
McNeal, R. (1998). High school extracurricular activities: Closed structures and stratifying patterns of participation. The Journal of Educational Research, 91, 183-191. doi:10. $1080 / 00220679809597539$

Meier, A., Hartmann, B. S., \& Larson, R. (2018). A Quarter Century of Participation in SchoolBased Extracurricular Activities: Inequalities by Race, Class, Gender and Age? Journal of Youth \& Adolescence, 47, 1299-1316. Doi: 10.1007/s10964-018-0838-1

Modecki, K. L., Barber, B. L., \& Eccles, J. S. (2014). Binge drinking trajectories across adolescence: for early maturing youth, extra-curricular activities are protective. Journal of Adolescent Health, 54, 61-66. doi: 10.1016/j.jadohealth.2013.07.032

Modecki, K. L., Blomfield Neira, C., \& Barber, B. L. (2018). Finding what fits: Breadth of participation at the transition to high school mitigates declines in self-concept. Developmental Psychology, 54, 1954-1970. doi: 10.1037/dev0000570

Monahan, K. C., Steinberg, L., Cauffman, E., \& Mulvey, E. P. (2009). Trajectories of Antisocial Behavior and Psychosocial Maturity From Adolescence to Young Adulthood. Developmental Psychology, 45, 1654-1668. Doi: 10.1037/a0015862

Morris, D. S. (2015). Actively Closing the Gap? Social Class, Organized Activities, and Academic Achievement in High School. Youth \& Society, 47, 267-290. doi: $10.1177 / 0044118 \times 12461159$

Murnen, S. K., \& Kohlman, M. H. (2007). Athletic participation, fraternity membership, and sexual aggression among college men: A meta-analytic review. Sex Roles, 57, 145-157. Doi: 10.1007/s11199-007-9225-1

O’Donnell, A. W., \& Barber, B. L. (2018). Exploring the association between adolescent sports participation and externalising behaviours: The moderating role of prosocial and risky peers. Australian Journal of Psychology, 70, 361-368. Doi: 10.1111/ajpy.12203 
Piotrowska, P. J., Stride, C. B., Croft, S. E., \& Rowe, R. (2015). Socioeconomic status and antisocial behavior among children and adolescents: a systematic review and metaanalysis. Clinical Psychology Review, 35, 47-55. doi: 10.1016/j.cpr.2014.11.003

Rose-Krasnor, L., Busseri, M. A., Willoughby, T., \& Chalmers, H. (2006). Breadth and Intensity of Youth Activity Involvement as Contexts for Positive Development. Journal of Youth and Adolescence, 35, 385-399. doi: 10.1007/s10964-006-9037-6

Roth, J. L., \& Brooks-Gunn, J. (2003). What exactly is a youth development program? Answers from research and practice. Applied Developmental Science, 7, 94-111. Doi: 10.1207/S1532480XADS0702_6

Simpkins, S. D., Fredricks, J. A., \& Eccles, J. S. (2012). Charting the Eccles' expectancy-value model from mothers' beliefs in childhood to youths' activities in adolescence. Developmental Psychology, 48, 1019-1032. Doi: 10.1037/a0027468

Spruit, A., Kavussanu, M., Smit, T., \& IJntema, M. (2019). The relationship between moral climate of sports and the moral behavior of young athletes: A multilevel meta-analysis. Journal of Youth \& Adolescence, 48, 228-242. Doi: 1007/s10964-018-0968-5

Stanton-Salazar, R. D. (2011). A social capital framework for the study of institutional agents and their role in the empowerment of low-status students and youth. Youth \& Society, 43, 10661109. doi: 10.1177/0044118X10382877

Stearns, E., \& Glennie, E. J. (2010). Opportunities to participate: Extracurricular activities’ distribution across and academic correlates in high schools. Social Science Research, 39, 296-309. doi: 10.1016/j.ssresearch.2009.08.001

Steinberg, D. B., \& Simon, V. A. (2019). A Comparison of Hobbies and Organized Activities among Low Income Urban Adolescents. Journal of Child and Family Studies, 28, 11821195. Doi: 10.1007/s10826-019-01365-0 
Tommaso, A., \& Longobardi, S. (2017). Equality of Educational Opportunities, Schools’ Characteristics and Resilient Students: An Empirical Study of EU-15 Countries Using OECD-PISA 2009 Data. Social Indicators Research, 134, 917-953. Doi: 10.1007/s11205016-1464-5

Viau, A., Denault, A., \& Poulin, F. (2015). Organized activities during high school and adjustment one year post high school: Identifying social mediators. Journal of Youth \& Adolescence, 44, 1638-1651. Doi: 10.1007/s10964-014-0225-5

Weininger, E. B., Lareau, A. \& Conley, D. (2015). What money doesn't buy: Class resources and children's participation in organized extracurricular activities. Social Forces, 94, 479-503. Doi: $10.1093 /$ sf/sov071

White, A. M., \& Gager, C. T. (2007). Idle Hands and Empty Pockets? Youth Involvement in Extracurricular Activities, Social Capital, and Economic Status. Youth \& Society, 39, 75111. doi: $10.1177 / 0044118 X 06296906$

Wichstrom T, Wichstrom L. (2009). Does sports participation during adolescence prevent later alcohol, tobacco and cannabis use? Addiction, 104, 138-149. Doi: 10.1111/j.13600443.2008.02422.x. 
Table 1.

Descriptive Statistics and Pearson Correlations between Externalizing Behaviors at Time 1 and 2, and Socioeconomic Status $(N=388)$.

\begin{tabular}{lccccc}
\hline & $\begin{array}{c}\text { Mean }(S D) \\
{[\text { Range] }}\end{array}$ & 1. & 2. & 3. & 4. \\
\hline 1. Externalizing & $1.37(0.72)$ & - & & \\
Behaviors (T2) & {$[1-8]$} & & & \\
2. Externalizing & $1.30(0.54)$ & $.50 * *$ & - & \\
Behaviors (T1) & {$[1-6]$} & & & - \\
3. Socioeconomic & $10.60(0.98)$ & $-.15^{*}$ & -.07 & & \\
Status & {$[8.15-11.72]$} & $.11^{*}$ & $.13^{*}$ & -.04 & -.06 \\
4. Gender
\end{tabular}

$* \mathrm{p}<.05$ level; ** $\mathrm{p}<.001$ level.

${ }^{\dagger} 0=$ Female, 1 = Male 
Table 2

A Multinominal Logistic Regression Analysis Examining if Time 1 Externalizing Behaviors, Socioeconomic Status, Pubertal Timing, and Gender Predict Activity Status (N=397).

\begin{tabular}{lcccc}
\hline & \multicolumn{2}{c}{ Swap } & \multicolumn{2}{c}{ Remain } \\
& $\mathrm{B}(\mathrm{SE})$ & Wald's $\chi^{2}$ & $\mathrm{~B}(\mathrm{SE})$ & Wald's $\chi^{2}$ \\
\hline $\begin{array}{l}\text { Externalizing Behaviors } \\
\text { (T1) }\end{array}$ & $-.32(.30)$ & 1.14 & $.01(.23)$ & $<.01$ \\
Socioeconomic Status & $.41^{*}(.15)$ & 7.54 & $.49^{* *}(.14)$ & 13.12 \\
Gender $^{\dagger}$ & $-.24(.31)$ & .58 & $-.60^{*}(.28)$ & 4.57 \\
\hline
\end{tabular}

Note: Drop-Out is the reference group.

$* \mathrm{p}<.05$ level; ** $\mathrm{p}<.01$ level.

${ }^{\dagger} 0=$ Female, $1=$ Male 
Table 3.

A Moderated Regression Analysis Investigating the Conditional Relationship between Socioeconomic Status and Activity Status when Predicting Subsequent Externalizing Behaviors $(N=388)$.

\begin{tabular}{|c|c|c|c|c|c|c|}
\hline & \multicolumn{3}{|c|}{ Step 1} & \multicolumn{3}{|c|}{ Step 2} \\
\hline Variables & $\mathrm{B}(\mathrm{SE})$ & $\beta$ & $s r^{2} \%$ & B (SE) & $\beta$ & $s r^{2} \%$ \\
\hline $\begin{array}{l}\text { Externalizing } \\
\text { Behaviors (T1) }\end{array}$ & $.65 * *(.06)$ & .49 & $23.23 \%$ & $.65 * *(.06)$ & .49 & $22.84 \%$ \\
\hline $\begin{array}{l}\text { Socioeconomic } \\
\text { Status }\end{array}$ & $-.06 *(.03)$ & -.09 & $0.72 \%$ & $-.07 *(.03)$ & -.09 & $0.81 \%$ \\
\hline Gender $^{\dagger}$ & $.05(.07)$ & .03 & $0.11 \%$ & $.04(.07)$ & .03 & $0.07 \%$ \\
\hline $\mathrm{D}_{\text {Swap }}{ }^{\mathrm{a}}$ & $-.34 * *(.09)$ & -.21 & $2.56 \%$ & $-.27 * *(.09)$ & -.17 & $1.59 \%$ \\
\hline D Remain $^{b}$ & $-.31 * *(.08)$ & -.22 & $2.76 \%$ & $-.25 * *(.08)$ & -.18 & $1.64 \%$ \\
\hline $\begin{array}{l}\mathrm{D}_{\text {Swap }} \mathrm{X} \\
\text { Socioeconomic } \\
\text { Status }\end{array}$ & & & & $.25 * *(.09)$ & .15 & $1.30 \%$ \\
\hline $\begin{array}{l}\text { D Remain X }_{\text {Xocioeconomic }} \\
\text { Status }\end{array}$ & & & & $.23 * *(.08)$ & .16 & $1.39 \%$ \\
\hline
\end{tabular}

$* \mathrm{p}<.05$ level; $* * \mathrm{p}<.01$ level.

${ }^{\dagger} 0=$ Female, $1=$ Male

a $1=$ Swap, $0=$ Drop-Out, $0=$ Remain

b $1=$ Remain, $0=$ Drop-Out, $0=$ Swap, 


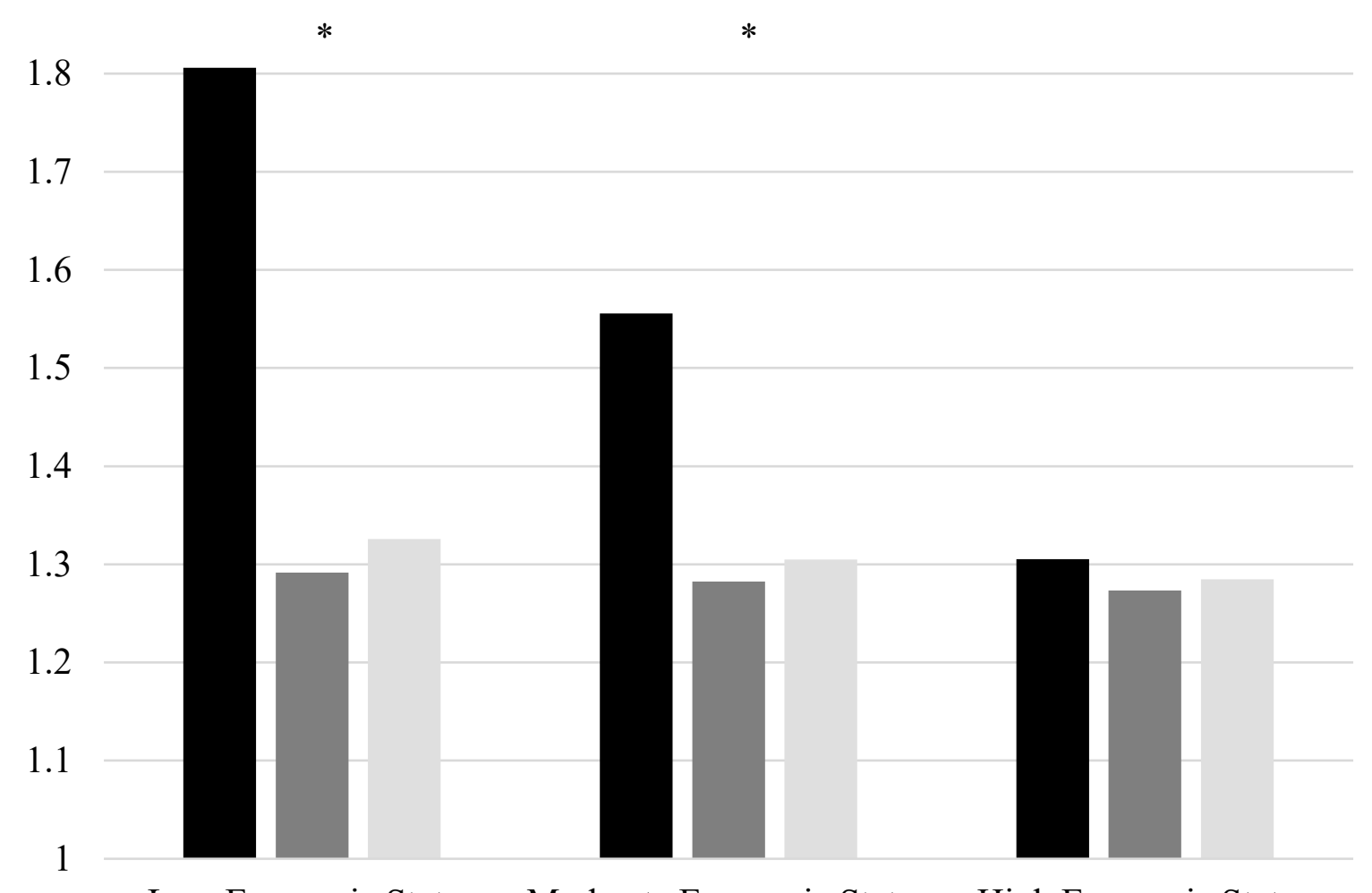

Low Economic Status Moderate Economic Status High Economic Status

- DropOut Swap Remain

Figure 1. Externalizing behaviors (Time two) as a function of activity status dependent upon whether the adolescents attended a low, moderate, or high economic status school. Previous externalizing behaviors and gender were statistically controlled.

Note: $* p<.05$ 